\title{
Impact of sense of coherence on oral health-related quality of life among Brazilian adults
}

\section{Evely Sartorti da SILVA(a) \\ Rosana de Fátima POSSOBON(a) \\ Marcela Di Moura BARBOSA(b) \\ Marília Jesus BATISTA(c) \\ Livia Maria Andaló TENUTA(d)}

(a) Universidade de Campinas - UNICAMP, Piracicaba Dental School, Department of Community Dentistry, Piracicaba, SP, Brazil.

(b) Universidade de Campinas - UNICAMP, Piracicaba Dental School, Department of Prosthodontics and Periodontics, Piracicaba, SP, Brazil.

(c)Faculdade de Medicina de Jundiaí, Department of Community Health, Jundiaí, SP, Brazil.

(d) University of Michigan, School of Dentistry, Department of Cariology, Restorative Sciences and Endodontics, Ann Arbor, MI, USA.

Declaration of Interests: The authors certify that they have no commercial or associative interest that represents a conflict of interest in connection with the manuscript.

Corresponding Author:

Evely Sartorti da Silva

E-mail: evelysartorti@yahoo.com.br

Submitted: March 6, 2019

Accepted for publication: September 1, 2019

Last revision: September 27, 2019
Abstract: It has been postulated that oral health-related quality of life (OHRQoL) may be affected by the sense of coherence (SOC), but there are no epidemiological studies investigating this association in Brazilian adults. The present study was conducted among adults of a mid-sized Brazilian city, with the aim of looking into this association. The probability sampling consisted of 342 adults aged 35-44 years old, from a mid-sized Brazilian city, who were examined at their homes for caries (Decayed, Missing and Filled Teeth [DMFT] Index) and periodontal disease (Community Periodontal Index - CPI), according to WHO criteria. The questionnaire applied included demographic factors, socioeconomic information, use of dental services, behavior, SOC and the Oral Health Impact Profile (OHIP). The OHIP outcome, measured by prevalence of the impact, was analyzed by binary logistic regression using a hierarchical approach, a conceptual model, and a 5\% significance level. A total of $67.9 \%$ of the respondents had one or more impacts on OHRQoL, and $54.4 \%$ showed a high SOC. The impact on OHRQoL was more prevalent in adults who had a manual occupation (PR $=2.47,95 \% C I$ 1.24-4.93), those who perceived the need for dental treatment $(\mathrm{PR}=2.93,95 \% \mathrm{CI}$ 1.67-5.14), and those who had untreated caries $(\mathrm{PR}=1.93,95 \% \mathrm{CI} 1.07-3.47)$. Those with a low SOC had a twofold higher prevalence of impact on OHRQoL ( $P R=2.19,95 \% C I$ 1.29-3.71). This impact on OHRQoL was associated with a low SOC, even after adjusted by socioeconomic, behavioral and clinical factors. Future studies should consider the SOC in determining the oral health impact on quality of life.

Keywords: Behavioral Sciences; Oral Health; Psychology; Quality of Life; Epidemiology.

\section{Introduction}

According to the Global Burden of Disease (GBD) 2010 Study, the impact of oral diseases ranks among the top 100 worldwide diseases on a list totaling 291. It is well known that socioeconomic deprivation affects the occurrence of oral diseases, and the interpretation of their impact. ${ }^{2}$ However, the presence of oral diseases and unfavorable socioeconomic factors are not enough to explain the multidimensional and multifactorial oral health impact on quality of life, usually referred to as the oral health-related quality of life (OHRQoL). 
In epidemiological studies measuring the OHRQoL in adults using the Oral Health Impact Profile (OHIP) questionnaire ${ }^{3}$ associations have been found with socioeconomic factors, such as income, age, education, gender and ethnicity, as well as oral health conditions, such as dental loss, need for prosthetic rehabilitation, periodontitis and caries lesions ${ }^{4}$. In addition, the OHIP was associated with general health conditions, oral health behaviors, perception of the need for dental treatment, and psychosocial factors like the sense of coherence (SOC). ${ }^{4}$

The SOC evaluates how individuals give meaning to the world (understanding), recognize and use available resources to respond to a demand (management), and feel that these answers make sense emotionally (meaning). ${ }^{5} \mathrm{~A}$ high SOC reflects good adaptive ability of human beings to deal with stress, thus prompting people to stay well, or satisfied with their quality of life, even under adverse and stressful situations. ${ }^{5,6}$ Epidemiological studies with adults have identified similar clinical and socioeconomic factors associated with a high SOC and a low OHIP.,8 In fact, a high SOC is usually associated with the adoption of healthy oral health-related behaviors, which would change the clinical state of the individual, and his subjective interpretation of the importance of oral health., ${ }^{910,11}$

The influence of SOC on OHRQoL impacts was assessed in a study on a representative sample of the Finnish population, ${ }^{12}$ whereby an association of the SOC with all dimensions of the OHIP was found, especially psychological discomfort, psychological incapacity and handicap. The authors of the study found that a low SOC would lead to a high impact on OHRQoL, regardless of oral health conditions, healthy behaviors or socioeconomic factors. ${ }^{12}$ Other authors have also detected the same relationship between SOC and OHIP, , ${ }^{713}$ in two studies, the ability to cope with stress caused by oral diseases mediated this association. ${ }^{8,10}$ Thus, inclusion of the SOC in a study assessing OHRQoL can promote a better understanding of the psychosocial aspects that might modify the interpretation of this impact. There are no studies that have investigated the association between SOC and OHRQoL in epidemiological studies with a probabilistic sampling in Brazil.
In addition, it should be taken into account that socioeconomic, demographic and even cultural differences between populations may alter the interpretation of both the OHRQoL and the SOC. Therefore, the objective of this study was to determine the effect of SOC on the OHRQoL, after adjusting for conditions of oral health, oral health-related behaviors and socioeconomic factors in Brazilian adults.

\section{Methodology}

\section{Ethical issues}

This study was conducted following the standards required by Brazilian regulations (Resolution 466/2012) on research in humans, and was approved by the Research and Ethics Committee of the Piracicaba Dental School - UNICAMP, on September 9, 2013 (protocol \# 077/2013).

\section{Study location}

The study was conducted in the municipality of Jundiaí. According to the last census, conducted by the Brazilian Institute of Geography and Statistics (IBGE) in 2010, the number of inhabitants in Jundiaí, state of São Paulo, was 370,126, and the human development index was 0.857 (considered very high in comparison with other Brazilian cities). The planning stages and calibration of examiners occurred in 2013, and the data were collected in 2014.

\section{Sample}

The sample comprised adults aged between 35 and 44 years, which is considered the default age for evaluating oral health conditions in adults, according to the World Health Organization (WHO) ${ }^{14}$ This study was part of a larger project entitled "Epidemiological Surveys of Oral Health - Jundiai/SP 2014."

Sample size was calculated from the mean DMFT, and the periodontal disease data was obtained from the National Oral Health Survey, SB-Brasil 2010, Southeast region. ${ }^{15}$ An error of $10 \%$, a design effect (deff) of 2, and a 95\% confidence level were adopted. Calculations were adjusted to take into account a population size of 56,668 inhabitants in this age group (according to the IBGE). Moreover, a $50 \%$ prevalence of high SOC also was considered 
in the sample calculation and corresponded to the highest and final value. After adding a sample loss of $30 \%$, considering possible losses and refusals, the minimum sample size was established at 300 .

The inclusion criteria were as follows: resident of Jundiaí, SP, aged between 35 and 44 years, cognitive ability to answer the questionnaire, and agreement to participate in the study. The exclusion criterion was individuals lacking cognitive ability to answer the questions assessed during the interview.

Participants were selected by a probabilistic sampling of households. Initially, 30 census regions and 2 substitute regions, involving both urban and rural areas, were chosen by sampling interval. The number of households was calculated considering the likelihood that one adult having the required age would be found in every two households visited, ${ }^{16}$ resulting in a number of 20 participants per census region. These households were randomly selected by a sample interval. The participant to be included had to be at home, either at the time of the visit, or during a conveniently scheduled appointment.

The clinical examinations were carried out at home, under natural lighting, without prophylaxis or prior drying, with CPI probes and intraoral mirrors, as recommended by the WHO. ${ }^{14}$ The examiners comprised 5 dentists and 3 assistants, hired by the municipality. All were trained and calibrated in a 16-h theoretical and $64 \mathrm{~h}$ practical training course. The percentage of agreement for the dental caries examination ranged from $80.4 \%$ to $99.2 \%$ (kappa 0.72 to 0.98 ), and for presence of periodontal disease, from $63 \%$ to $91 \%$ (kappa 0.63 to 0.76 ), which is considered a substantial or high agreement, according to Landis and Koch. ${ }^{17}$

\section{Variables}

This was a cross-sectional, observational study. The outcome was the OHIP, measured by the 14-question instrument (OHIP-14), applied in the form of interviews. The responses for each question ranged as follows: 0 = never, 1 = hardly ever, 2 = occasionally, 3 = fairly often, and $4=$ very often. ${ }^{3,18}$ The evaluation of the questionnaires considered the absence or presence of an impact, in that absence was so considered when all responses were " 0 ," and presence, when there was at least one response from " 1 to 4 " to any of the questions. ${ }^{19}$

The main independent variable of interest was the SOC, which was investigated using its 13-question transculturally adapted version (SOC-13). ${ }^{6}$ The questions include the 5 to 1 responses on a Likert scale. The correction of the questionnaires was performed after the reversal of scores of questions 4, 5, 6, 7, 8, 9, 10,11 and 12 . The sum of SOC values of the individual responses can range from 13 to 65 , with the median being considered the cut-off between a low and a high SOC. ${ }^{11}$ In questionnaires in which fewer than three questions were blank, the average value of the other answers was used in the blank questions..$^{20}$ The higher the value found, the better the individual's adaptive ability; conversely, the lower the value, the worse his adaptive ability. Moreover, data on clinical, demographic and socioeconomic variables, as well as use of dental services, were collected and used in a model, as possible predictor, confounding or effect modifier variables.

The conceptual theoretical model organized the variables into hierarchical blocks (Figure). ${ }^{20,21}$ The first block of the model included the exogenous variables of ethnicity (self-reported as white or not white [black, yellow, brown or indigenous]), age (35-39 or 40-44 years) and gender (male or female).

The second block included the primary determinants of oral health, described as follows: a) Availability of services and information on oral health: type of service used (private, insurance or public), and preventive guidance on oral health (whether it was ever received); b) Personal characteristics: civil status (partner or no partner), family income (> 4 minimum wages [MW] [MW was approximately US\$210.00/month at the time of the study], 2 to $4 \mathrm{MW}$ and < $2 \mathrm{MW}$ ), number of people living in the same home ( $\leq 4$ or $>5$ people), level of education (high: university degree, middle: high school or vocational school; or low: less than high school), occupation of the respondent (non-manual or manual occupation, or having no activities, like pensioners or unemployed individuals), and SOC (high or low); and c) Characteristics of the environment: treated and fluoridated water (whether received or not received). 


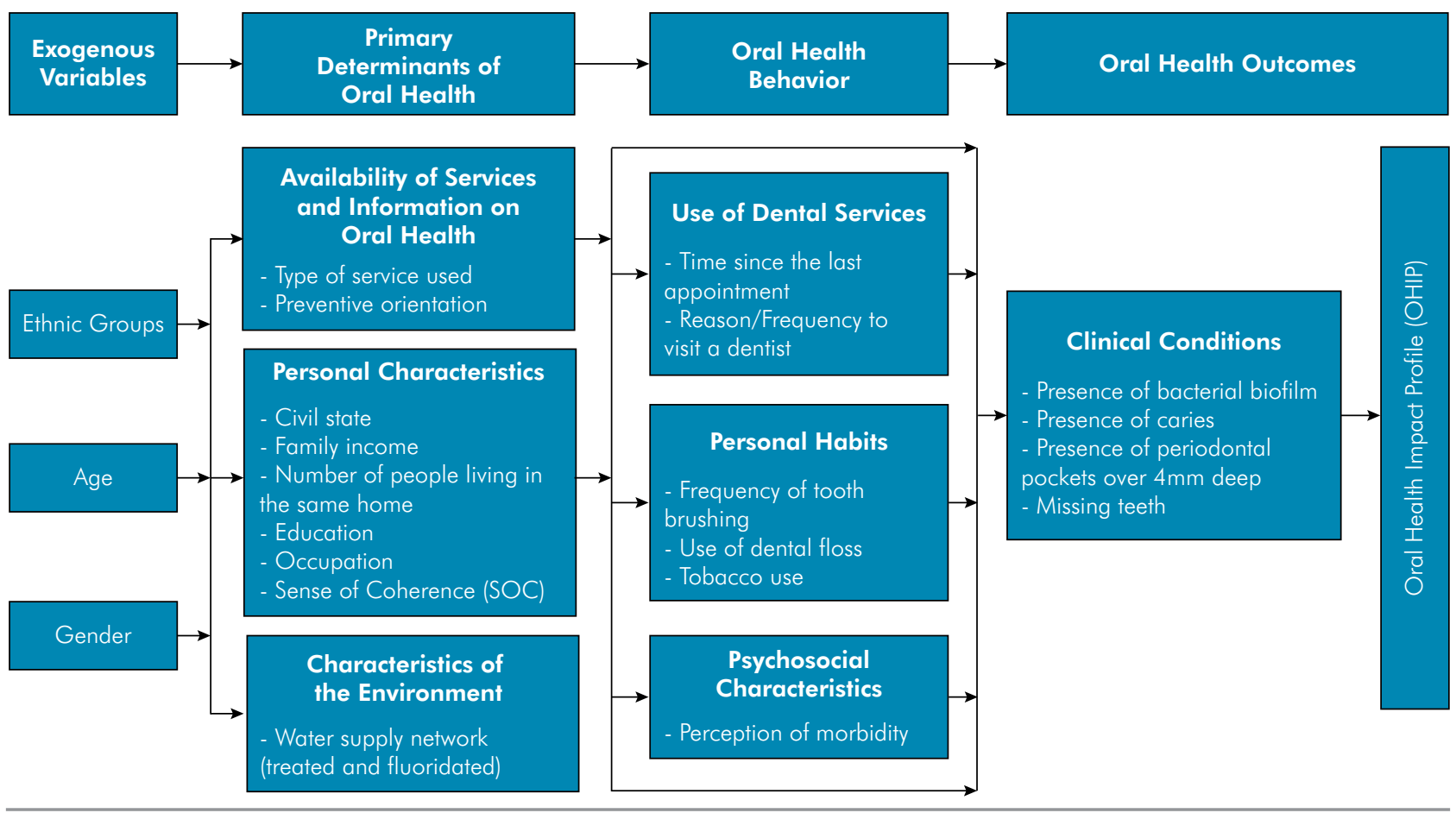

Figure. Adapted conceptual framework for the Oral Health Impact Profile outcome. ${ }^{21}$

The third block addressed the variables representing oral health behaviors, described as: a) Use of dental services ( $<1$ year, 1 to 2 years, or $>3$ years since last visit), and the reason for/ frequency of visits to the dentist (routine, pain, or does not go to the dentist); b) Personal habits: toothbrushing ( 3 or more times per day or up to 2 times per day), daily flossing (yes or no), and smoking (yes or no); and c) Psychosocial characteristics: perception of morbidity (feeling a need or no need for dental treatment at the time).

The fourth block grouped the independent, clinically observed variables, such as dental biofilm in one or more sextants of the mouth, or else its absence in all sextants, ${ }^{22}$ caries (caries component of the DMFT index), periodontal pockets over 4-mm deep in at least 1 sextant (measured by the Community Periodontal Index - CPI), and missing teeth (between 0 and 4 , or more than 5 , being dichotomized in the third quartile). ${ }^{14}$ The last block contained the outcome variable of impact on OHRQoL, assessed by the OHIP.

\section{Statistical model and analysis}

The data was organized in an Excel® datasheet. Statistical analyses were performed using the
Statistical Package for the Social Sciences (SPSS) version 20.0. Simple descriptive statistics were used to describe the sample, with absolute and percentage distribution of the variables studied.

Bivariate analyses were made to assess the outcome of presence of impact on OHRQoL, considering the prevalence of any impact on one or more questions, or else absence of impact, based on single binary logistic regression. The main explanatory variable was SOC, dichotomized using the median between high and low. Then multivariate analyses were performed using hierarchical binary logistic regression, according to the adapted theoretical model. The variables that showed statistical significance of $5 \%$ were maintained and adjusted by those that presented p-value $<0.20$. Each block of variables adjusted the subsequent block of variables, to obtain the final model.

\section{Results}

Although there was a non-response rate of $48.4 \%$ for the households, the residents of 330 households in the 32 test regions were examined, resulting in 342 examined adults. They corresponded to adults 
within the age group range, and with cognitive ability to answer the questionnaire.

Table 1 describes the sampling characteristics. A higher prevalence of women $(67.1 \%)$ and people living with a partner $(69.3 \%)$ were found. The family income of $44.4 \%$ of those examined was $\geq 4 \mathrm{MW}$, and the number of people living in the same house was between 1 and 4 in $75.1 \%$ of the cases. A middle level of schooling (38.9\%) and a non-manual occupation $(56.7 \%)$ prevailed. Most of the respondents used private services $(67 \%)$ and had visited the dentist for the last time sometime in the past year (53.5\%), but many of those surveyed (74.9\%) still believed they needed dental treatment. Most of the respondents claimed that they brushed their teeth 3 times a day (73.4\%), and flossed daily (60.2\%). However, $61.4 \%$ of them presented dental biofilm in one or more sextants. Untreated caries and periodontal pockets of $>4 \mathrm{~mm}$ were present in $36.5 \%$ and $24.3 \%$ of the sample, respectively. Seventy-five percent of the sample presented fewer than 5 missing teeth. The SOC score ranged from 37 to 62 , for an average of $49.31(\mathrm{SD}=5.79$ ), and a median of 50 and $54 \%$, representing a high SOC prevalence. The prevalence of any impact measured by the OHIP was $67.9 \%$.

Table 2 presents the results of the bivariate analyses between the OHIP and independent variables of the proposed model. A significant association ( $\mathrm{p} \leq 0.05)$ was found with gender, ethnicity, family income, education, occupation, SOC, reason for/ frequency of visits to the dentist, toothbrushing, perception of morbidity, presence of bacterial biofilm, and presence of caries. Variables with a p level $\leq 0.20$ were also kept in the model.

The results of the multivariate analyses using a hierarchical approach are shown in Table 3. The SOC and occupation results from block 1 were used to adjust block 2, and the SOC, occupation, perception of needs and toothbrushing results of this block were used to adjust block 3 . The dental caries were included in block 3 to complete the final adjusted model. After making multivariate regression adjustments, the impact on OHRQoL was found to be more prevalent in adults who had a manual occupation (prevalence ratio $[\mathrm{PR}]=3.07$, confidence interval $[\mathrm{CI}] 95 \% \mathrm{CI}$ 1.54-6.11), in those who perceived the need for dental treatment ( $\mathrm{PR}=3.37,95 \% \mathrm{CI} 2.00-5.83)$, and those who had untreated caries ( $P R=1.93,95 \% C I 1.07-3.47)$. The SOC was maintained in the model after the three blocks were adjusted; those who presented a low SOC had a twofold higher prevalence of impacts on OHRQoL (PR = 2.19, 95\%CI 1.29-3.71).

\section{Discussion}

The present study showed an association between a low SOC and its impact on OHRQoL. This means that there was a higher prevalence of low SOC among the individuals who had more impacts on quality of life. In addition to SOC, socioeconomic, behavioral and clinical variables were also associated with an impact on OHRQoL. This demonstrates the importance of a conceptual theoretical model for determining outcomes like OHRQoL, which are multidimensional and depend on multiple contextual factors.

The absence of an impact on OHRQoL was reported in the present study by $32.1 \%$ of respondents. Some of the participants had a hard time classifying similar answers like "hardly ever" and "occasionally"; accordingly, the answer "never" was used to report the absence of an impact ${ }^{19}$. Two studies with European adults reported a prevalence of approximately $60-70 \%$ of the answer "not at all" and "very seldom," a depiction not considered as representing a problem by its authors. ${ }^{8,12}$ Even considering methodological, socioeconomic, clinical, psychosocial and cultural differences, which could interfere with the self-perception of impact in these two studies, as well as in the present study, the SOC maintained an inverse relationship with the impacts on OHRQoL. This emphasizes the validity of this kind of study in different socioeconomic and cultural contexts.

The association between impacts in OHRQoL and clinical variables, such as untreated caries, periodontal diseases and dental loss in adults, has been widely reported in the literature, mainly concerning pain and psychological incapacity directly caused by oral diseases. ${ }^{4,19}$ However, it has been suggested that the presence of these conditions has little influence on the perception of OHRQoL by Brazilian adults ${ }^{23}$. Similar results were found in the present study, in which only the presence of untreated caries remained significantly 
Table 1. Demographic, socioeconomic, psychosocial and clinical characteristics of adult residents in Jundiaí, Brazil, 2014.

\begin{tabular}{|c|c|c|c|}
\hline \multirow{2}{*}{$\begin{array}{l}\text { Variable blocks } \\
\text { Exogenous variables }\end{array}$} & $\mathrm{n}(\%)$ & Variable blocks & $\mathrm{n}(\%)$ \\
\hline & \multicolumn{2}{|r|}{ 3. Characteristics of the environment } & \\
\hline \multicolumn{2}{|l|}{ Gender } & Water supply network & \\
\hline Male & $111(32.5)$ & Treated and fluoridated & $288(84.2)$ \\
\hline Female & $231(67.5)$ & Not treated & $54(15.8)$ \\
\hline Total & $342(100)$ & Oral Health Behavior & \\
\hline Ethnicity & & 1. Use of dental services & \\
\hline White skin & $241(70.5)$ & Time since last appointment & \\
\hline Not white skin & $100(29.2)$ & $<1$ year & $183(53.5)$ \\
\hline Age & & Between 1 and 2 years & $96(28.1)$ \\
\hline 35-39 years old & $187(54.7)$ & $>3$ years & $63(18.4)$ \\
\hline $40-44$ years old & $155(45.3)$ & Reason/Frequency of visits to the dentist & \\
\hline \multicolumn{2}{|c|}{ Primary determinants of oral health } & Routine & 215 (62.9) \\
\hline \multirow{2}{*}{\multicolumn{2}{|c|}{ 1. Availability of services and information on oral health }} & Pain & 114 (33.3) \\
\hline & & Does not go to the dentist & $13(3.8)$ \\
\hline \multicolumn{2}{|l|}{ Type of service used } & 2. Personal habits & \\
\hline Private & $229(67)$ & Frequency of toothbrushing & \\
\hline Insurance & 65 (19) & $\geq 3$ times per day & $251(73.4)$ \\
\hline Public & $46(13.5)$ & $<2$ times per day & $91(26.6)$ \\
\hline \multicolumn{2}{|c|}{ Preventive orientation on oral health } & Use of dental floss & \\
\hline Not received & $62(18.1)$ & No & $136(39.8)$ \\
\hline Received & $279(81.6)$ & Yes & $206(60.2)$ \\
\hline \multicolumn{2}{|l|}{ 2. Personal characteristics } & Tobacco use & \\
\hline \multicolumn{2}{|l|}{ Civil status } & No & $283(82.7)$ \\
\hline Partner & $237(69.3)$ & Yes & $58(17)$ \\
\hline No partner & $101(29.5)$ & 3. Psychosocial characteristics & \\
\hline \multicolumn{2}{|l|}{ Family income } & Perception of morbidity & \\
\hline$>4$ minimum wages & $152(44.4)$ & No & $83(24.3)$ \\
\hline 2-4 minimum wages & 99 (28.9) & Yes & $256(74.9)$ \\
\hline$<2$ minimum wages & $66(19.3)$ & Oral Health Outcomes & \\
\hline Number of people living & & Presence of bacterial biofilm & \\
\hline$\leq 4$ people & $257(75.1)$ & Yes & $210(61.4)$ \\
\hline$>5$ people & $83(24.3)$ & No & $132(38.6)$ \\
\hline Education level & & Presence of untreated caries & \\
\hline High & $103(30.1)$ & Yes & $125(36,5)$ \\
\hline Middle & $133(38.9)$ & No & $217(63,5)$ \\
\hline Low & $94(27.5)$ & Presence of periodontal pockets & \\
\hline Occupation & & (over 4-mm deep) & \\
\hline Not manual & $194(56.7)$ & Yes, at least 1 sextant & $83(24.3)$ \\
\hline Manual & $85(24.9)$ & No & 259 (75.7) \\
\hline With no activities & $61(17.8)$ & Missing Teeth & \\
\hline Sense of Coherence $\mathrm{SOC}$ & & 5 to 32 missing teeth & $141(41.2)$ \\
\hline High & $185(54.4)$ & 0 to 4 missing teeth & $200(58.5)$ \\
\hline Low & $155(45.6)$ & Presence of Impacts on OHIP & \\
\hline & & No & $109(32.1)$ \\
\hline & & Yes & $231(67.9)$ \\
\hline
\end{tabular}

Note: Variables that did not complete $100 \%$ percentage values represent missing cases. 
Table 2. Bivariate analyses and $p$ value for presence and absence of impact in adults of Jundiaí, Brazil, 2014.

\begin{tabular}{|c|c|c|c|}
\hline \multirow{2}{*}{ Variable blocks } & \multirow{2}{*}{$\begin{array}{c}\text { Absence of impacts } \\
\mathrm{n}(\%)\end{array}$} & \multirow{2}{*}{$\begin{array}{c}\text { Presence of impacts } \\
\mathrm{n}(\%)\end{array}$} & \multirow{2}{*}{ p-value } \\
\hline & & & \\
\hline \multicolumn{4}{|l|}{ Exogenous variables } \\
\hline \multicolumn{4}{|l|}{ Gender } \\
\hline Male & $44(39.6)$ & $67(60.4)$ & 0.04 \\
\hline Female & $66(28.6)$ & $165(71.4)$ & \\
\hline \multicolumn{4}{|l|}{ Ethnicity } \\
\hline White skin & $86(35.7)$ & $155(64.3)$ & 0.036 \\
\hline Not white skin & $24(24.0)$ & $76(76.0)$ & \\
\hline \multicolumn{4}{|l|}{ Age } \\
\hline 35-39 years old & $62(33.2)$ & $125(66.8)$ & 0.666 \\
\hline 40-44 years old & $48(31.0)$ & $107(69.0)$ & \\
\hline \multicolumn{4}{|l|}{ Primary determinants of oral health } \\
\hline \multicolumn{4}{|l|}{ Personal characteristics } \\
\hline \multicolumn{4}{|l|}{ Civil status } \\
\hline Partner & $83(35.0)$ & $154(65.0)$ & 0.095 \\
\hline No partner & $26(25.7)$ & $75(74.3)$ & \\
\hline \multicolumn{4}{|l|}{ Family income } \\
\hline$>4$ minimum wages & $57(37.5)$ & $95(62.5)$ & 0.002 \\
\hline 2-4 minimum wages & $31(31.3)$ & $68(68.7)$ & \\
\hline$<2$ minimum wages & $9(13.6)$ & $57(86.4)$ & \\
\hline \multicolumn{4}{|c|}{ Number of people living in the same house } \\
\hline$\leq 4$ people & $80(31.1)$ & $177(68.9)$ & 0.657 \\
\hline$>5$ people & $28(33.7)$ & $55(66.3)$ & \\
\hline \multicolumn{4}{|l|}{ Education level } \\
\hline High & $42(40.8)$ & $61(59.2)$ & 0.042 \\
\hline Middle & $40(30.1)$ & $93(69.9)$ & \\
\hline Low & $23(24.5)$ & $71(75.5)$ & \\
\hline \multicolumn{4}{|l|}{ Occupation } \\
\hline Not manual & $81(41.8)$ & $113(58.2)$ & $<0.001$ \\
\hline Manual & $14(16.5)$ & $71(83.5)$ & \\
\hline No activities & $14(23.0)$ & $47(77.0)$ & \\
\hline \multicolumn{4}{|l|}{ Sense of Coherence (SOC) } \\
\hline High & $74(40.0)$ & $111(60.0)$ & 0.001 \\
\hline Low & $35(22.6)$ & $120(77.4)$ & \\
\hline \multicolumn{4}{|l|}{ Oral health behavior } \\
\hline \multicolumn{4}{|l|}{ Use of dental services } \\
\hline \multicolumn{4}{|l|}{ Time since last appointment } \\
\hline$<$ than 1 year & $54(29.5)$ & $129(70.5)$ & 0.105 \\
\hline Between 1 and 2 years & $39(40.6)$ & $57(59.4)$ & \\
\hline$>3$ years & $17(27.0)$ & $46(73.0)$ & \\
\hline \multicolumn{4}{|c|}{ Reason/Frequency of visits to the dentist } \\
\hline Routine & $81(37.7)$ & $134(62.3)$ & 0.018 \\
\hline Pain & $26(22.8)$ & $88(77.2)$ & \\
\hline Does not go to the dentist & $3(23.1)$ & $10(76.9)$ & \\
\hline
\end{tabular}




\begin{tabular}{|c|c|c|c|}
\hline \multirow{2}{*}{ Variable blocks } & Absence of impacts & Presence of impacts & \multirow{2}{*}{ p-value } \\
\hline & $\mathrm{n}(\%)$ & $n(\%)$ & \\
\hline \multicolumn{4}{|l|}{ Personal habits } \\
\hline \multicolumn{4}{|l|}{ Frequency of toothbrushing } \\
\hline$\geq 3$ times per day & $93(37.1)$ & $158(62.9)$ & 0.001 \\
\hline$<2$ times per day & $17(18.7)$ & $74(81.3)$ & \\
\hline \multicolumn{4}{|l|}{ Use of dental floss } \\
\hline No & $37(27.2)$ & 99 (72.8) & 0.111 \\
\hline Yes & $73(35.4)$ & $133(646)$ & \\
\hline \multicolumn{4}{|l|}{ Tobacco use } \\
\hline No & $96(33.9)$ & $187(66.1)$ & 0.087 \\
\hline Yes & $13(22.4)$ & $45(77.6)$ & \\
\hline \multicolumn{4}{|l|}{ Psychosocial characteristics } \\
\hline \multicolumn{4}{|l|}{ Perception of morbidity } \\
\hline No & $47(56.6)$ & $36(43.4)$ & $<0.001$ \\
\hline Yes & $62(24.2)$ & $194(75.8)$ & \\
\hline \multicolumn{4}{|l|}{ Oral health outcomes } \\
\hline \multicolumn{4}{|l|}{ Presence of dental biofilm } \\
\hline Yes & $59(28.1)$ & $151(71.9)$ & 0.042 \\
\hline No & $51(38.6)$ & $81(61.4)$ & \\
\hline \multicolumn{4}{|l|}{ Presence of untreated caries } \\
\hline Yes & $24(19.2)$ & $101(80.8)$ & $<0.001$ \\
\hline No & $86(39.6)$ & $131(60.4)$ & \\
\hline \multicolumn{4}{|c|}{ Presence of periodontal pockets (over 4-mm deep) } \\
\hline Yes, at least 1 sextant & $20(24.1)$ & $63(75.9)$ & 0.071 \\
\hline No & $90(34.7)$ & $169(65.3)$ & \\
\hline \multicolumn{4}{|l|}{ Missing teeth } \\
\hline 5-32 missing teeth & $46(32.6)$ & $95(67.4)$ & 0.903 \\
\hline 0-4 missing teeth & $64(32.0)$ & $136(68.0)$ & \\
\hline
\end{tabular}

associated with the OHII. The same clinical condition can beinterpreted and managed differently, and have different meanings, depending on the SOC of the individual, and can present different impacts on OHRQoL, because of subjective and multidimensional aspects.

Although not all clinical variables were associated with the OHRQoL, the perception of positive morbidity had a high influence on the impact. Other studies also showed that there are discrepancies between real needs and those referred to by the patient ${ }^{25}$. This suggests that the interpretation of the impact of illness can be considered as subjective, and may not always be linked to clinical and epidemiological disease detection.

Concerning the socioeconomic factors already established in the literature as determinants for health, as well as the risk factors for disease development ${ }^{2}$ and for a high impact on OHRQoL, ${ }^{4,23}$ the present study also showed that people who worked in manual occupations had a greater impact on OHRQoL. The WHO considers occupation as an intermediate determinant for health, and is directly connected to income and education level; therefore, it can also serve to determine access to health services and other resources. ${ }^{26}$ The fact that these determinants did not reduce the influence of SOC on OHRQoL may confirm the salutogenic assumption that socioeconomic factors would not change the individual perception of quality of life in adults. ${ }^{5}$ Therefore, individuals with good oral health may perceive it negatively, owing to a low SOC, regardless of their socioeconomic status. 


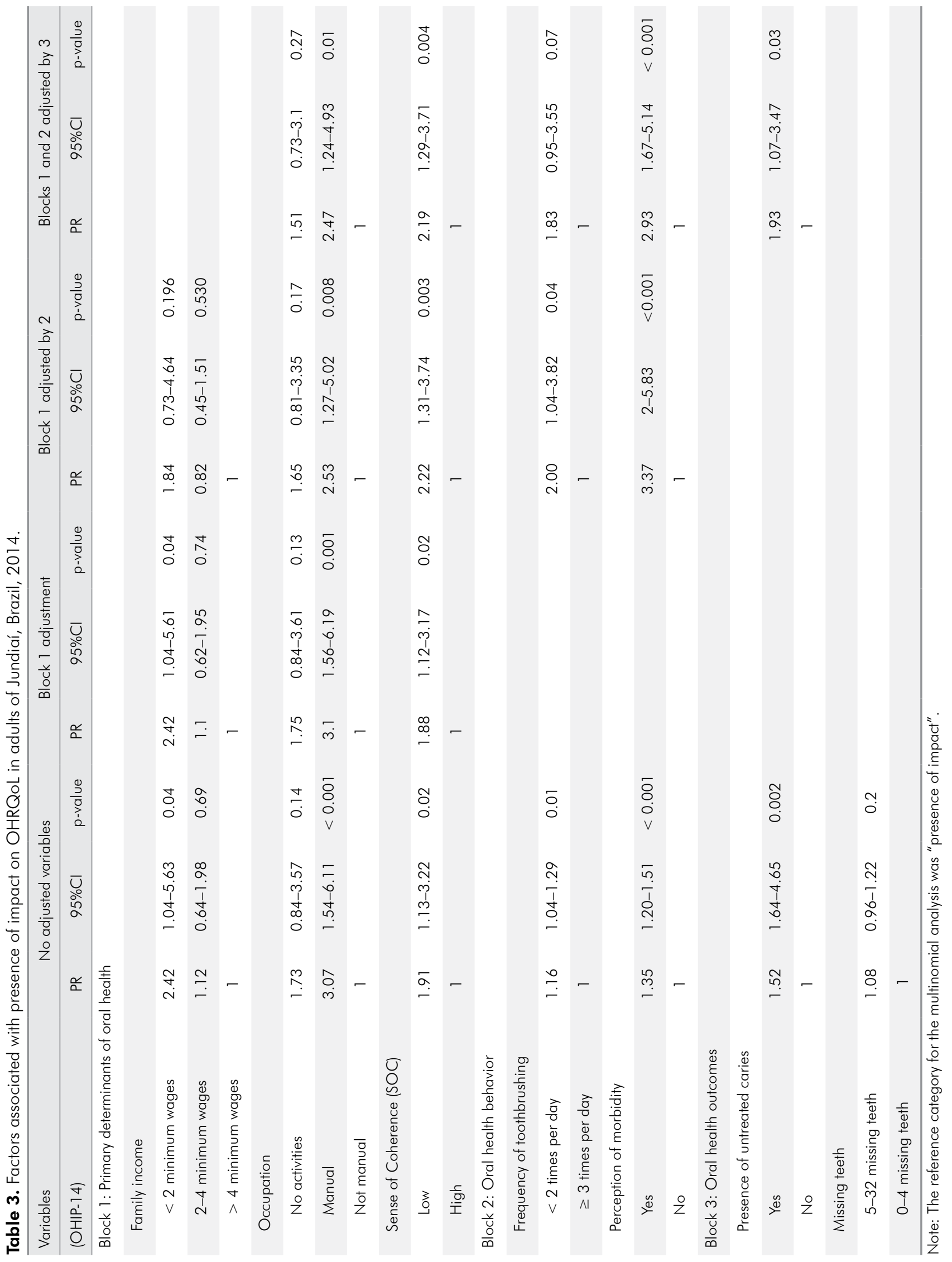


Based on these results, it would be worthwhile to suggest that changes be made in the oral health practices directed at adults. If these practices are focused only on the clinical outcomes and the prevention of diseases risk factors, without considering OHRQoL and SOC, the objectives of oral health promotion will not be achieved, and the changes in behavior will be less substantial and shorter lasting. The effort to direct oral health care actions toward a better, overall understanding of its benefits by human beings, considering their beliefs and the socioeconomic and cultural context, may help humanize oral health care and bring it closer to the population, reduce differences and promote long-lasting healthy oral behaviors. ${ }^{24,27}$ Although still incipient, studies that aim to improve SOC in adults assert that health promotion actions should focus on the "empowerment" of individuals to identify appropriate resources to cope with stressors, and encourage reflection on stressful situations, so as to render them comprehensible, manageable and meaningful. Every stressful situation that is successfully managed will increase the SOC, improving the prospects for successfully facing new situations that present new stressors. ${ }^{28}$

One limitation of the present study was the proportion of men to women examined, since it may not fully characterize the profile of the population. A greater number of women than men is common in home sampling studies, and emphasizes the representability of the present study sampling procedure. Moreover, considering the cross-sectional design of the study, it was suggested that the analysis of this subject be made by qualitative and interventional studies.

\section{Conclusion}

In the present study, there were a greater number of adults with a low sense of coherence, among those who showed a higher prevalence of impacts on OHRQoL. Untreated caries, manual occupation and positive perception of morbidity were also associated with the impact on OHRQoL. The results suggest that the SOC should be considered in further qualitative and interventional studies assessing the impact of oral health on quality of life.

\section{Acknowledgments}

This study was based on a Masters thesis presented by the first author to the Graduate Program in Community Health Management, Piracicaba Dental School, University of Campinas, Brazil. We wish to thank the Oral Health Coordination represented by Luiz Carlos Miyashiro, and the Government and Management School of the Municipality of Jundiaí for supporting this study. We would also like to thank the organizers, Maria Cristina Sciamarelli and Jane Rodrigues de Campos Tonetti, and all those who participated in this study.

\section{References}

1. Marcenes W, Kassebaum NJ, Bernabé E, Flaxman A, Naghavi M, Lopez A, et al. Global burden of oral conditions in 1990-2010: a systematic analysis. J Dent Res. 2013 Jul;92(7):592-7. https://doi.org/10.1177/0022034513490168

2. Watt RG, Sheiham A. Integrating the common risk factor approach into a social determinants framework. Community Dent Oral Epidemiol. 2012 Aug;40(4):289-96. https://doi.org/10.1111/j.1600-0528.2012.00680.x

3. Slade GD. Derivation and validation of a short-form oral health impact profile. Community Dent Oral Epidemiol. 1997 Aug;25(4):284-90. https://doi.org/10.1111/j.1600-0528.1997.tb00941.x

4. Gabardo MC, Moysés ST, Moysés SJ. [Self-rating of oral health according to the Oral Health Impact Profile and associated factors: a systematic review]. Rev Panam Salud Publica. 2013 Jun;33(6):439-45. Portuguese.

5. Antonovsky A. Unraveling the mystery of health: How people manage stress and stay well. San Francisco: Jossey-Bass; 1987. (Jossey Bass Social and Behavioral Science Series).

6. Bonanato K, Branco DB, Mota JP, Ramos-Jorge ML, Paiva SM, Pordeus IA, et al. Trans-Cultural Adaptation and Psychometric Properties of the "Sense of Coherence Scale" in Mothers of Preschool Children. Interam J Psychol. 2009;43(1):144-53.

7. Johansson V, Axtelius B, Söderfeldt B, Sampogna F, Paulander J, Sondell K. Multivariate analyses of patient financial systems and oral health-related quality of life. Community Dent Oral Epidemiol. 2010 Oct;38(5):436-44. https://doi.org/10.1111/i.1600-0528.2010.00546.x 
8. Boman UW, Wennström A, Stenman U, Hakeberg M. Oral health-related quality of life, sense of coherence and dental anxiety: an epidemiological cross-sectional study of middle-aged women. BMC Oral Health. 2012 Jun;12(1):14. https://doi.org/10.1186/1472-6831-12-14

9. Bernabé E, Watt RG, Sheiham A, Suominen-Taipale AL, Nordblad A, Savolainen J, et al. The influence of sense of coherence on the relationship between childhood socioeconomic status and adult oral health-related behaviours. Community Dent Oral Epidemiol. 2009 Aug;37(4):357-65. https://doi.org/10.1111/ן.1600-0528.2009.00483.x

10. Gupta E, Robinson PG, Marya CM, Baker SR. Oral Health Inequalities: Relationships between Environmental and Individual Factors. J Dent Res. 2015 Oct;94(10):1362-8. https://doi.org/10.1177/0022034515592880

11. Davoglio RS, Abegg C, Fontanive VN, Oliveira MM, Aerts DR, Cavalheiro CH. Relationship between Sense of Coherence and oral health in adults and elderly Brazilians. Braz Oral Res. 2016 May;30(1):1-9. https://doi.org/10.1590/1807-3107BOR-2016.vol30.0056

12. Savolainen J, Suominen-Taipale AL, Hausen H, Harju P, Uutela A, Martelin T, et al. Sense of coherence as a determinant of the oral health-related quality of life: a national study in Finnish adults. Eur J Oral Sci. 2005 Apr;113(2):121-7. https://doi.org/10.1111/j.1600-0722.2005.00201.x

13. Machado FW, Perroni AP, Nascimento GG, Goettems ML, Boscato N. Does the Sense of Coherence modifies the relationship of oral clinical conditions and Oral Health-Related Quality of Life? Qual Life Res. 2017 Aug;26(8):2181-7. https://doi.org/10.1007/s11136-017-1558-9

14. World Health Organization. Oral Health Surveys Basic Methods. 4th ed. Geneva; World Health Organization; 1997.

15. Brasil. SB Brazil 2010: national research on oral health: main results. Brasília, DF: Livromapas; 2014.

16. Roncalli AG, Silva NN, Nascimento AC, Freitas CH, Casotti E, Peres KG, et al. [Relevant methodological issues from the SBBrasil 2010 Project for national health surveys]. Cad Saude Publica. 2012;28 Suppl:s40-57. Portuguese. https://doi.org/10.1590/S0102-311X2012001300006

17. Landis JR, Koch GG. The measurement of observer agreement for categorical data. Biometrics. 1977 Mar;33(1):159-74. https://doi.org/10.2307/2529310

18. Oliveira BH, Nadanovsky P. Psychometric properties of the Brazilian version of the Oral Health Impact Profile-short form. Community Dent Oral Epidemiol. 2005 Aug;33(4):307-14. https://doi.org/10.1111/j.1600-0528.2005.00225.x

19. Batista MJ, Perianes LB, Hilgert JB, Hugo FN, Sousa ML. The impacts of oral health on quality of life in working adults. Braz Oral Res. 2014;28(1):1-6. https://doi.org/10.1590/1807-3107BOR-2014.vol28.0040

20. Suominen S, Helenius H, Blomberg H, Uutela A, Koskenvuo M. Sense of coherence as a predictor of subjective state of health: results of 4 years of follow-up of adults. J Psychosom Res. 2001 Feb;50(2):77-86. https://doi.org/10.1016/S0022-3999(00)00216-6

21. Andersen RM, Davidson PL. Ethnicity, aging, and oral health outcomes: a conceptual framework. Adv Dent Res. 1997 May;11(2):203-9. https://doi.org/10.1177/08959374970110020201

22. Ainamo J, Bay I. Problems and proposals for recording gingivitis and plaque. Int Dent J. 1975 Dec;25(4):229-35.

23. Bandeca MC, Nadalin MR, Calixto LR, Saad JRC, Silva SRC. Correlation between oral health perception and clinical factors in a Brazilian community. Community Dent Health. 2011 Mar;28(1):64-8. https://doi.org/10.1922/CDH_2485Bandéca05

24. Slade GD. Are dental health behaviors rational, after all? J Dent Res. 2013 Jan;92(1):5-6. https://doi.org/10.1177/0022034512462579

25. Lundegren N. Oral health and self-perceived oral treatment need of adults in Sweden. Swed Dent J Suppl. 2012;(223):10-76.

26. Marmot M, Friel S, Bell R, Houweling TA, Taylor S; Commission on Social Determinants of Health. Closing the gap in a generation: health equity through action on the social determinants of health. Lancet. 2008 Nov;372(9650):1661-9. https://doi.org/10.1016/S0140-6736(08)61690-6

27. Miettola J, Vilianen AM. A salutogenic approach to prevention of metabolic syndrome: a mixed methods population study. Scand J Prim Health Care. 2014 Dec;32(4):217-25. https://doi.org/10.3109/02813432.2014.982372

28. Super S, Wagemakers MA, Picavet HS, Verkooijen KT, Koelen MA. Strengthening sense of coherence: opportunities for theory building in health promotion. Health Promot Int. 2015 Jul;(1):dav071. https://doi.org/10.1093/heapro/dav071 